\title{
CULTURA PATRIMONIALISTA E POLÍTICA URBANA: O DESAFIO DO DIREITO À CIDADE E À MORADIA
}

\author{
Ivone Silva ${ }^{1}$
}

Resumo: $\mathrm{O}$ artigo propõe uma abordagem crítica da cultura patrimonialista brasileira como entrave à efetivação do direito à cidade e à moradia, ou seja, mecanismo de segregação urbana. A análise teórica reportar-se-á ao conceito de direito à cidade em Harvey e Lafebvre e o direito à moradia como garantia constitucional da dignidade da pessoa humana. A metodologia fez uso do método lógico dedutivo, com procedimentos através da pesquisa exploratória, bibliográfica e documental. Ao fim, verificou-se que o modelo patrimonialista historicamente promoveu a garantia do direito à propriedade privada em detrimento da sua função social consolidada no ideal de justiça e equidade.

Palavras-chaves: Patrimonialismo; Direito Humano à Cidade; Direito à Moradia; Direito à Propriedade; Política Urbana.

\section{PATRIMONIALIST CULTURE AND URBAN POLICY: THE CHALLENGE OF THE RIGHT TO CITY AND DWELLING}

\begin{abstract}
The article proposes a critical approach of the Brazilian patrimonial culture as an obstacle to the realization of the right to the city and housing, ie urban segregation mechanism. Theoretical analysis report shall be the concept of right to the city in Harvey and Lafebvre and the right to housing as a constitutional guarantee of human dignity. He was employed deductive logic method, exploratory procedures literature and documents. Finally, it was verified that patrimonialism historically promoted the guarantee of the right to private property to the detriment of its social function consolidated in the ideal of justice and equity.
\end{abstract}

Keywords: Patrimonialism; Human Right to the City; Right to Housing; Right to Property; Urban Policy.

\footnotetext{
${ }^{1}$ Mestranda em Direito - História do Pensamento Jurídico - Historicidade dos Direitos Fundamentais pela Faculdade Damas, Especialista em Gestão Pública e Controle, Direito Público e Direito Eleitoral, Advogada, https://orcid.org/0000-0001-7077-4069, contato: ivmsilva@gmail.com .
} 


\section{INTRODUÇÃO}

O Brasil formou-se através de um processo histórico de viés patrimonial, no qual os resquícios de colonialidade persistem, não condizentes com as demandas sociais, contribuindo para a desigualdade distributiva que permeia nosso território e a população de desvalidos, em especial aqueles que lutam por direito à moradia digna, favorecendo o crescimento da segregação urbana e a favelização, consequência dos deslocamentos urbanos e rurais. Ademais, historicamente a concentração do Direito em promover a garantia da propriedade privada e não da moradia, esteve sempre presente na própria Constituição, demonstrando que os interesses individuais e privados se sobrepõem aos interesses da coletividade.

$\mathrm{Na}$ sociedade contemporânea brasileira fenômenos múltiplos ocorrem para dar sentido ao progresso da civilização, vivenciando uma época onde os aglomerados urbanos são cada vez mais crescentes, haja vista a migração rural-urbana que ocorreu de forma desordenada, dando lugar à segregação urbana e gentrificação. Do mesmo modo, a garantia do direito humano ou fundamental à cidade e à moradia, aliado ao aprimoramento das legislações urbanísticas, expressa o debate sócio-jurídico que surge como resposta às exigências de uma sociedade mais plural e de consciência cidadã.

A propriedade é um grande foco de tensão entre as correntes ideológicas do liberalismo e do igualitarismo, mas há de se destacar a previsão constitucional do inciso XXIII do artigo $5^{\circ}$, que traz uma inovação: a função social da propriedade no bojo dos direitos e garantias fundamentais. Assim, a partir do momento em que o ordenamento jurídico reconheceu que o exercício da propriedade deveria ser protegido no interesse coletivo da sociedade, sua função precípua é combater desigualdades.

Propõe-se no presente artigo abordar criticamente a cultura patrimonialista no Brasil como desafio à efetivação do direito à cidade e à moradia digna, bem como a atual política urbana com o Programa "Minha Casa Minha Vida" lançado em 2009 pelo Governo Federal. Para tanto, utiliza-se uma proposta metodológica fundamentada na análise das legislações e bibliografias relevantes para a compreensão da problemática proposta, partindo-se da literatura especializada existente sobre a temática.

Como consequência o tema foi desenvolvido na expectativa de demonstrar a importância da análise do contexto normativo e práxis como requisito imprescindível para efetivar os direitos humanos e fundamentais à moradia digna e da cidade e que dentre as várias nuances que compõe o Direito Urbanístico, o tema torna-se oportuno também diante do 
panorama político atual que deve ser pensada como política de Estado e não de Governo, envolvendo todos os atores que vivenciam cotidianamente à cidade.

Sendo assim, a sociedade brasileira tem o direito de discutir e se manifestar, e dentro deste panorama previamente apresentado, resta-se ainda, verificar sua aplicabilidade face ao processo urbano no que concerne a dinâmica do Programa "Minha Casa Minha Vida".

\section{DIREITO FUNDAMENTAL E HUMANO À CIDADE E À MORADIA}

Conceitualmente os direitos fundamentais são percebidos de várias maneiras, que segundo Marques (2014, p.151) indicam os pensamentos dominantes de cada época e que suas garantias passam a ser produto da racionalidade, que até então provinham de uma visão mítica, e que enquanto ordem passa pela compreensão dos valores que a fundaram (Marques, 2014, p. 152). O caráter mutável, imperfeito e relativo da experiência humana permite proceder múltiplas interpretações dessa historicidade (WOLKMER, 2014, p.12), portanto, no traço histórico os direitos fundamentais advieram em fases, e a doutrina adotou a expressão dimensão, em detrimento do termo geração de direito, por entender que várias dimensões coexistem, não havendo superação entre elas, propondo uma visão conjunta dos direitos fundamentais, encontrando-se condicionados, havendo assim, uma relação de reciprocidade.

Com o passar do tempo novos valores ditam a ordem dos direitos fundamentais, que da liberdade e da busca pela igualdade, surge à solidariedade e/ou cooperação, considerados a terceira dimensão de direitos fundamentais, estabelecendo direitos e deveres por parte de seus titulares de direitos - a transindividualidade solidária adotando uma perspectiva comunitária dos direitos fundamentais, exigindo um agir solidário. Assim, os direitos de terceira dimensão relacionam-se a interesses coletivos e difusos, expandindo a noção de cidadania. Destaque-se que os direitos fundamentais apresentam uma ordem objetiva de valores constitucionalmente protegidos baseados em princípios objetivos que expressam valores culturais (MARQUES, 2014, 163).

Já ideia do direito à cidade surge basicamente das ruas, dos bairros, como um grito de socorro e amparo de pessoas oprimidas em tempos de desespero (HARVEY, 2014, p. 15). Originalmente o conceito de direito à cidade foi definido em 1968 pelo sociólogo francês e filósofo marxista, Henri Lefebvre, em seu livro Le Droit à la Ville ${ }^{2}$, o direito de comandar todo

\footnotetext{
${ }^{2} \mathrm{O}$ Direito à Cidade
} 
o processo urbano, destacando ainda, como um direito de não exclusão da sociedade das qualidades e benefícios da vida urbana. Lefebvre (2001) repudia a maneira determinista e metafísica do urbanismo moderno limitada a questões espaciais, volvendo as dificuldades urbanas somente numa ação técnica, científica e administrativa, considerando uma segregação socioeconômica e o fenômeno de afastamento a alienação dos cidadãos, pois não são sujeitos de direito ao usufruto do espaço social, tendo em vista as relações econômicas de dominação e de políticas urbanísticas ordenadas e controladas pelo Estado.

Na década de 90 as ideias de Lefebvre são resgatadas nas áreas de geografia e planejamento urbano, tendo como principal defensor o geógrafo britânico marxista David Harvey (2012), traçando a função exercida pelo espaço urbano como canal de assimilação de capital excedente ao longo da história, em consonância com Lefebvre (2006), ampliando a concepção do direito à cidade como direito humano, incorporando àquele conceito novos conteúdos de natureza política.

Ademais, Harvey (2012, p. 86) destaca que o processo urbano tem intuito global, fazendo necessário um maior controle democrático sobre a produção e utilização do excedente, formando uma administração democrática sobre sua organização para estabelecer o direito à cidade, submetendo o Estado ao controle democrático, evitando assim, que o direito à cidade caia em atores privados ou em seus interesses. E que a urbanização sempre foi um fenômeno de classe, mas sua distribuição repousou em poucas mãos. A cidade antes era vista por seu valor de uso (fruição e beleza) e hoje é considerado espaço privado para realização do lucro.

Nessa década, o debate internacional quanto à questão dos Direitos Humanos na cidade assumiu formato de reivindicação do "direito à cidade" considerando as cidades como espaços coletivos avalistas de direitos humanos, através de um ingresso justo aos serviços essenciais e responsáveis pelas políticas de desenvolvimento local, derivando em muitas Cartas locais de direitos humanos, tais como: Carta Europeia para a Proteção dos Direitos Humanos na cidade, Saint-Denis - França, 2000, assinado por mais de 350 cidades europeias; Carta Mundial do Direito à Cidade, escrito pelos movimentos sociais reunidos no Fórum Social Mundial de Porto Alegre - Brasil, 2001; Carta dos Direitos e Responsabilidades de Montreal, Canadá, 2006; Carta da Cidade do México para o direito à cidade, Cidade do México, 2010; Carta dos Direitos Humanos de Gwangju, Coréia do Sul, em 2012.

Igualmente, a Carta-agenda mundial de Direitos Humanos na cidade, objetiva promover e fortalecer os direitos humanos de todos os habitantes em todas as cidades ao redor do mundo (Cidades e Governos Locais Unidos - CGLU, Comissão Inclusão Social, 
Democracia Participativa e Direitos Humanos, 2011), representando a unificação em escala mundial para operacionalizar, por meio de planos de ação, os direitos humanos na cidade. A carta aponta lançar ferramentas a serviço dos governos locais para a promoção da construção de sociedades mais inclusivas, democráticas e solidárias, envolvendo as pessoas de forma participativa. Assim como os outros direitos humanos, este é um direito interdependente.

Os direitos humanos independem de positivação, por conseguinte, o Direito à Cidade de Henri Lefebvre (2001) é definido como um direito de não exclusão da sociedade urbana das qualidades e benefícios da vida urbana. Nesta perspectiva, engaja-se uma sociedade onde todos os habitantes teriam o poder de modificar as decisões e as condições que afetam suas vidas, resultando em comunidades mais fortes. Lefevbre (2001) teoriza que "O Direto à Cidade" é uma crítica ao Estado que reproduz a segregação nas cidades através do próprio sistema que ele impõe sobre a sociedade, dando respostas desiguais às demandas da população de baixa renda no que concerne à habitação (Pagani, 2017), por exemplo. Assim o tecido urbano foi se transformando em um espaço onde as diferenças de classes são bastante visíveis, pois muitos não possuem o direito de morar com dignidade.

Para Harvey (2012, p. 74), a questão de que tipo de cidade nós queremos não anda divorciada das modalidades de laços sociais, estilos de vida, tecnologias e valores estéticos que a sociedade deseja. $\mathrm{O}$ direito à cidade vai muito além da liberdade individual de acesso a recursos urbanos:

\footnotetext{
é o direito de mudar a nós mesmos pela mudança da cidade. Além disso, é um direito comum antes de individual já que esta transformação depende inevitavelmente do exercício de um poder coletivo de moldar o processo de urbanização. A liberdade de construir e reconstruir a cidade e a nós mesmos é, como procuro argumentar, um dos mais preciosos e negligenciados direitos humanos (HARVEY, 2012, p.74).
}

Ressalte-se que o direito humano à cidade de segunda dimensão tem perspectiva social que integrou a carta da ONU nos anos 60 e desde então essa pauta de direito à cidade vem sendo debatida nos coletivos sociais.

Atualmente, século XXI, todos estão novamente se interrogando sobre as questões mais fundamentais sobre a sobrevivência e o desenvolvimento da humanidade. Uma vez que a urbanização é irreversível, as cidades serão o lugar de moradia, vida e trabalho da maioria da população, lugar privilegiado de difusão do progresso e das inovações - culturais, econômicas, sociais, científicas e tecnológicas e do bem-estar social. Ao longo das duas últimas décadas, novos paradigmas de desenvolvimento urbano foram construídos pela experiência prática e pelo saber coletivo de múltiplos atores sociais que fazem e refazem quotidianamente a cidade. 
É de se notar que os processos de globalização afetam diferentemente os lugares e as cidades, conforme seu posicionamento na rede mundial e seu potencial para dar respostas aos novos desafios econômicos, sociais e urbanos. Surgiram, em consequência, as chamadas cidades globais. A partir dos atributos das cidades globais, e do novo paradigma de desenvolvimento urbano, pode-se discutir o desafio que a globalização coloca para as demais cidades e quais as estratégias locais que vêm sendo adotadas para o seu enfrentamento na busca do desenvolvimento local sustentável.

Não obstante, em consequência da globalização, também essas cidades se caracterizam pela fragmentação dos seus espaços, onde se acentuam as desigualdades intraurbanas entre as áreas, que abrigam as novas atividades e segmentos populacionais direta ou indiretamente ligados à globalização da economia, e as áreas onde se localizam os setores e as populações marginalizadas por esse processo e também as que operam fora do sistema de mercado. Neste derradeiro, a efetivação do direito humano ou fundamental à cidade e à moradia no Brasil é um desafio para um país marcado pela concentração fundiária, ausência de saneamento, priorização de política de transporte individual em detrimento do coletivo, déficit habitacional e periferias violentas e desestruturadas.

\section{PATRIMONIALISMO, PROPRIEDADE PRIVADA E FUNÇÃO SOCIAL}

Segundo Faoro (2012), somos um povo que trata a coisa pública como se fosse privada. No Estado patrimonial a administração pública é tratada como particular, as relações são baseadas na confiança. Na estrutura patrimonialista brasileira, herdada dos lusitanos, as formações sociais ocorreram sempre com a presença do Estado na vida dos indivíduos. Porém o modelo reflete a vontade do príncipe que com os seus se apropriam do Estado para benefício próprio. Instala-se o "estamento burocrático" que é a elite administrativa, sendo considerada uma comunidade fechada de difícil ascendência ou descendência social.

Essa elite plutocrática é centralizadora e administra em prol dos seus, divergindo das noções da democracia e do que é justo e equânime nas relações sociais sem igualdade no tratamento com as classes sociais menos privilegiadas.

No livro Sabe com quem está falando? Luiz Ruffato (2012, p.14-15) traça suas considerações históricas quanto à temática:

O Brasil, desde seu achamento, convive com instituições políticas debilitadas pela apropriação do aparelho do estado pelas elites econômicas. (...) Assim, encastelada,

Rev. de Direito Urbanístico, Cidade e Alteridade | e-ISSN: 2525-989X | Porto Alegre | v. 4 | n. 2 | p. 53 - 67 | Jul/Dez. 2018 
conseguiu manter a grande maioria da população alijada das decisões de interesse geral, consolidando-se, com o tempo, a apatia que caracteriza a sociedade.

A nossa é uma historia de autoritarismo e violência. O Brasil-Colônia e o BrasilImpério desconheceram a participação popular. (...)

Promulgada a República, pouco mudou a situação do controle do poder. (...) E, a rigor, este período foi uma sucessão de ditaduras e regimes de exceção. (2012, p.14-15)

Já Holanda (1995), tipifica o brasileiro como o "homem cordial" incapaz de diferenciar seus assuntos particulares da dimensão pública, herdeiros de uma cultura patriarcal, com costume de subordinação à autoridade e descaso a coisa pública, débil de participação na política. O perfil do homem público traz para suas atividades públicas comportamentos paternalistas, pois nasceu com valores familiares, patriarcais e particularistas (HOLANDA, 1995, p.146).

Para Souza (2017, p.10), essas leituras retratam um equívoco:

a tradição inaugurada por Sérgio Buarque e arrasadoramente influente até hoje não percebe a ação das classes sociais, daí que tenham criado o "brasileiro genérico", o homem cordial de Sérgio Buarque ou o homem do "jeitinho brasileiro" para um DaMatta. (...) É por conta dessa inércia provocada pela força de concepções passadas que pensamos os problemas brasileiros sob a chave do patrimonialismo e do populismo, dois espantalhos criados para tornar possível a aliança antipopular que caracteriza o Brasil moderno desde 1930 (SOUZA, 2017, p.10).

O patrimonialismo no Brasil é responsável pela desigualdade distributiva que permeia nosso território e uma grande população de desfavorecidos que só pode explicar-se pela falta de direitos e não pela escassez de bens. O problema fundamental é o da organização da sociedade (NUNES, 2003, p.116). Noutro sentido, a Constituição Federal trouxe uma inovação: a função social da propriedade, sendo tratada na parte referente aos direitos e garantias fundamentais - art. $5^{\circ}$, inciso XXIII - e não mais somente na ordem econômica, como nas constituições anteriores. Entretanto, destaca-se que a nossa constituição cidadã, reflete uma antinomia, reproduzida no artigo 170, que trata da atividade econômica, em contraponto ao inciso XXIII do artigo $5^{\circ}$. Em um, dominante é o interesse individual, no outro, é o interesse social. Nessa ótica, a função da propriedade tornou-se social, a partir do momento em que o ordenamento jurídico reconheceu que o exercício da propriedade deveria ser protegido no interesse coletivo da sociedade, pois a grande modificação operada no direito de propriedade reside no fato de que a propriedade é caracterizada mais pela finalidade econômica e social do bem sobre a qual incide.

Portanto, a tutela do Estado, por meio do Direito, só deve garantir a defesa daquela propriedade que se adapte aos objetivos do próprio Estado, ao promover o bem comum, e é nesse contexto que se insere o princípio da função social da propriedade, que muda a concepção 
do direito de propriedade, incorporando à sua estrutura um caráter social, voltado à coletividade. Afinal, no patrimonialismo de Raymundo Faoro e de Sérgio Buarque, a elite vampiresca e má está "no Estado", tornando literalmente invisível o mandonismo real, primeiro dos proprietários rurais e depois dos urbanos (SOUZA, 2017, p. 54).

Seguindo o debate contemporâneo que envolve o direito à cidade e à moradia, tem-se a visão jurídico-institucional, abalizada no Estatuto da Cidade, na legislação brasileira infraconstitucional e nas premissas dos direitos e cidadania e da dignidade da pessoa humana, instituindo seus objetivos na construção de uma sociedade livre, justa e solidária; erradicação da pobreza e a marginalização e reduzir as desigualdades sociais e regionais ${ }^{3}$.

É importante a observação de que a segregação urbana tem avançado nos últimos anos, permitindo o crescimento desordenado de favelas, habitações em áreas irregulares e ocupações por parte da classe trabalhadora devido ao déficit habitacional existente, afinal, vivemos em um mundo no qual os direitos de propriedade privada e a taxa de lucro se sobrepõem a todas as outras noções de direitos em que se possa pensar (HARVEY, 2014, p. 27). A cidade transformou-se em uma mercadoria para aqueles que têm respaldo financeiro para usufruí-la e almeja-se que “(...) num espaço urbano cujo solo seja mais abrigo e menos exclusão” (FACHIN, 1996).

Para Harvey (2014) o direito à cidade caiu em mãos privadas ou interesses quase privados, restrito à pequena elite política e econômica, promovendo a cidade como destino turístico, pois a urbanização absorve capitais excedentes, em consonância com a cultura patrimonialista brasileira presente nos dias atuais.

\section{PROGRAMA MINHA CASA MINHA VIDA}

Se considerarmos a vivência de um constitucionalismo social que pugna em conciliar a busca da justiça social e do bem-estar coletivo (SOUZA NETO; SARMENTO, 2014, p. 84) observar-se-á que a Constituição Federal trata da política urbana nos artigos 182 e 183 e que com outras normas infraconstitucionais determinam a legislação urbanística que tem como viés o uso e a ocupação do solo urbano, objetivando a regulação da produção social do espaço urbano, haja vista que o território é fruto das relações sociais e não da natureza, aplicando-se a função social da propriedade privada.

\footnotetext{
${ }^{3}$ Constituição Federal de 1988 artigo $3^{\circ}$, incisos I e III.
} 
Nesse sentido, o direito à moradia positivada na Constituição e demais normas brasileira e internacionais, é um dos norteadores da política urbana e primordial para se obter a efetivação do direito à cidade, porém grande é o déficit habitacional brasileiro.

Em vigor desde 2001, o Estatuto da Cidade foi um marco legal que possibilitou pensar em políticas públicas urbana com diversos grupos, contextualizando a realidade vivenciada com o caráter tecnocrático dos planos diretores. Dessa forma:

Com a aprovação do Estatuto da Cidade, houve na década de 2000, evidências da importância da formulação de políticas urbanas pautadas na participação social, com avanços na adoção de iniciativas inclusivas e dialogadas no planejamento territorial, de modo a fortalecer a gestão democrática, a promoção do direito à cidade (direito de uso e apropriação) e sua função social (OLIVEIRA; LOPES; SOUSA, 2018, p. 326).

A partir da reflexão sobre o processo de urbanização e sua relação com as práticas vigentes de planejamento urbano, verificando-se o contexto socioeconômico, o Governo Federal em meados da década de 2000, para combater o déficit habitacional lançou sua política nacional habitacional com o Programa "Minha Casa, Minha Vida", ampliando os subsídios públicos para a construção de casas, para auxiliar o acesso à moradia a diversas famílias através de subsídios e taxas menores de juros, apresentando três níveis de financiamento de acordo com o rendimento familiar.

Ocorre que os habitacionais foram sendo construídos distante dos centros urbanos, com infraestrutura precária, mobilidade mínima, difícil acesso aos serviços essenciais de educação e saúde, mantendo segregados os moradores dessa região. Dessa forma reduz-se o usufruto do direito à cidade, ocasionado num processo de segregação residencial e gentrificação, processo em que os moradores são afastados do seu núcleo cultural quando as áreas centrais e/ou periféricas são remodeladas para atender a classes sociais mais favorecidas.

Nesse sentido afirma Zuñiga (2017, p.8);

Por eso no es raro que se hable del centro como un lugar abandonado, sujeto a la anarquía, al deterioro y a la falta de identidad. Entonces, la cotidianidad de la gente que habita el centro actualmente se le puede considerar como una señal de resistencia frente al proyecto hegemónico de recuperación comercial y "residencial" promovido desde los gobiernos estatales y municipales. Esta cruzada oficial para capitalizar y concentrar los espacios urbanos en beneficio de intereses privados poco a poco se ha estado fortaleciendo con los proyectos verticales que actualmente se están desarrollando en la Zona Metropolitana de Monterrey. ${ }^{4}$ (ZUÑIGA, 2017, p.8)

\footnotetext{
${ }^{4}$ É por isso que não é incomum falar do centro como um lugar abandonado, sujeito à anarquia, deterioração e falta de identidade. Então, a vida cotidiana das pessoas que vivem no centro atualmente pode ser considerado como um sinal de resistência ao projeto hegemônico de recuperação comercial e "residencial" promovida pelos governos estaduais e municipais. Este aqui Cruzada oficial para capitalizar e concentrar os espaços urbanos em benefício de interesses privados pouco a pouco vem se fortalecendo com os projetos verticais que estão sendo em desenvolvimento na área metropolitana de Monterrey. (Tradução livre)
}

Rev. de Direito Urbanístico, Cidade e Alteridade | e-ISSN: 2525-989X | Porto Alegre | v. 4 | n. 2 | p. 53 - 67 | Jul/Dez. 2018 
Nesse sentido, os governos municipais se configuram como um dos campos de disputa atravessados pela presença destes novos atores coletivos que insurge pela efetivação do direito à moradia. São os enfrentamentos, as rupturas com a velha ordem, quando existem, que apontam o caráter inovador desses governos, aos quais se expressam de diferentes formas, para atender ao direito à moradia em seu princípio basilar da dignidade da pessoa humana. $\mathrm{O}$ fato a considerar é que independente da positivação do direito à moradia nos instrumentos legais, a questão do local da moradia vai além do "teto", pois as moradias precisam está cercadas de infraestrutura urbana básica em suas dimensões social, cultural e econômica.

Pois bem. O aparato estatal no seu bojo traz mecanismo da legalização da exceção com restrições de direitos fundamentais, regulados pela lógica do mercado empresarial com a flexibilização dos parâmetros urbanísticos. Para a classe trabalhadora, a cidade é compreendida como valor de uso. Já os capitais produzem e exploram o espaço urbano por atribuírem à cidade valor de troca (ESTEVES; PEREIRA, 2017). Assim, vislumbra-se um estado de exceção ou aporia onde os atos cometidos durante o iustitium ${ }^{5}$ que inexecuta o direito, rompendo-o para salvá-lo em caso de estado de necessidade? Ou devo considerar como pensamento abissal? Porque eu devo respeitar uma ordem legal que me priva de tudo? Assim, a ideia de intangibilidade dos direitos, sustentada pela justiça como equidade parece mais apropriada a atender às demandas da democracia constitucional (LOIS, 2005, p. 139).

Apesar da ampliação dos gastos públicos da política econômica no âmbito habitacional para acesso à moradia e usufruto do direito à cidade persiste ainda a crise urbana. Essa crise tem origem nas permanências e persistências de um modelo excludente, predatório e patrimonialista (ROLNIK, 2015, p. 266).

\section{CONSIDERAÇÕES FINAIS}

Os direitos humanos são obra de um aprendizado histórico da humanidade, constituindo-se em uma referência jurídica de todos os países do mundo, a partir da Declaração Universal dos Direitos Humanos de 1948, fruto de várias origens e que se sustentam nos mais variados alicerces, podendo ser definido como direitos essenciais para que o indivíduo seja tratado com dignidade, sem distinções, configurando amparo contra os abusos do poder público ou privado. O Estado deve promover e/ou proteger esses direitos humanos e fundamentais.

\footnotetext{
${ }^{5}$ Interrupção, suspensão do direito. Romper o direito para salvá-lo em caso de estado de necessidade.
} 
Igualmente, os princípios e valores dos quais permeiam os direitos humanos e fundamentais compreende o entrelaçamento de seu alicerce centrado na dignidade humana e assentado na positivação, permitirá a máxima efetivação desses direitos à cidade e à moradia com autonomia, ao qual nos remonta a reflexão kantiana de que a dignidade humana aliada a autonomia, justifica a validade universal dos direitos humanos a partir do seu princípio fundante.

Dessa forma, o valor da igualdade são à base dos direitos fundamentais de segunda dimensão quais os direitos sociais, econômicos e culturais, solicitando a atuação Estatal, porém, no Brasil, tais direitos ainda carecem de efetividade, pois eles representam direitos subjetivos individuais que proporciona igualdade material.

Ressalte-se que a Constituição Federal de 1988 tratou a habitação de forma indireta, e após recepcionar tratados internacionais quanto ao tema, ganha status constitucional através da emenda n. ${ }^{\circ} 26$ em 2000. Assim, o direito à moradia foi reconhecido como um direito humano fundamental, sendo essencial a garantia desse direito atrelado ao princípio da dignidade humana que pressupõe condições materiais mínimas para sua efetivação.

Ademais, a função social da propriedade passa-se a ser vista como uma necessidade social, atendendo aos preceitos constitucionais vinculados nos artigos 182 e 183 da Carta Magna, passando a missão aos municípios de desenvolverem políticas urbanas adequadas ao bem estar da comunidade, investindo na infraestrutura e serviços públicos essenciais de qualidade, tais como: saúde, educação, transporte, segurança, cultura; e que apesar de todos os esforços, a política nacional de habitação ainda continua excluindo os mais pobres da sociedade em detrimento de alguns citadinos, não atendendo o objetivo do pleno desenvolvimento das funções sociais da cidade e garantir o bem-estar de seus habitantes ${ }^{6}$. E oferecer moradia condizente ao princípio constitucional de dignidade da pessoa humana é uma questão de fazer a coisa certa, alocando bens para recompensar e promover igualdade.

Evidencia-se ainda que derivou-se da nova política habitacional brasileira ao propor o Programa "Minha Casa Minha Vida" para que cidadãos tivessem acesso à moradia, solucionando o déficit habitacional, porém verifica-se que houve um reforço no processo de periferização e, por conseguinte, exclusão desses grupos dos centros urbanos estabilizados, pois o patrimonialismo sempre funcionou como uma forma de dominação política, onde o trato da

\footnotetext{
${ }^{6}$ Constituição Federal de 1988 artigo 182.
} 
coisa pública confundia-se com o trato de seus bens privados, exercendo uma dominação tradicional de origem consuetudinária, não havendo espaço para o indivíduo.

Em última análise, o modelo patrimonialista vivenciado atualmente pelo Brasil está pautado por uma dominação tradicional, resultando em malefícios a sociedade priorizando os interesses individuais aos da coletividade, em especial no que tange ao direito humano à cidade e à moradia em respeito ao princípio da dignidade da pessoa humana, independentemente da sua positivação, historicamente concentrado em promover e perseguir o direito à propriedade privada em detrimento da sua função social, acarretando em segregação residencial, déficit habitacional e gentrificação, além da omissão do Estado em propor ações positivas através de políticas públicas urbanas consolidadas no ideal de justiça e equidade.

\section{REFERÊNCIAS}

BORGES, Antonio Marcos Soares. Minha Casa, Minha Vida, meu lar. Será mesmo? Uma visão sobre as recentes políticas habitacionais de interesse social e suas ações além das telhas e tijolos. 2018. Originalmente apresentada como dissertação de mestrado, Universidade Federal do Rio Grande do Sul, Porto Alegre: 2018. Programa de Pós-Graduação em Educação em Ciências: Química da Vida e Saúde. Orientação Prof. ${ }^{a}$ Dr. ${ }^{a}$ Cibele Schwanke.

CAVALCANTI, Francisco. Apreciação crítica aos direitos fundamentais de primeira geração à luz do direito de propriedade: da propriedade liberal à propriedade social. Direitos humanos e fundamentais em perspectiva. Cláudio Brandão, coordenador. São Paulo: Atlas, 2014, p. 239261.

CORONAS, mariana Celorio Suárez. Desposesión de derechos humanos em lãs democracias contemporáneas. In: XXXI CONGRESSO ALAS URUGUAY 2017. México, 2017. Resumos... ref. 0097 Disponível em: <http://alas2017.easyplanners.info/opc/tl/0097_mariana_celorio.pdf. Acesso em: 24 jun. 2018.

DUARTE, Maurizete Pimentel Loureiro; DUARTE, Gerson Constância; SIQUEIRA, Maria da Penha Smarzaro. A redemocratização no Brasil e a descentralização da política social de habitação. In: XXXI CONGRESSO ALAS URUGUAY 2017. México, 2017. Resumos... ref. 6815 Disponível em: <http://alas2017.easyplanners.info/opc/pdfs/ALAS_2017_Uruguay_LIBRO_de_RESUMENE S.pdf> Acesso em: 24 jun. 2018.

ESTEVES, Juliana Teixeira; PEREIRA, Maria Clara Bernardes. O direito à moradia no contexto da reestruturação produtiva. In: XXXI CONGRESSO ALAS URUGUAY 2017. México, 2017. Resumos... ref. 9001 Disponível em: <http://alas2017.easyplanners.info/opc/pdfs/ALAS_2017_Uruguay_LIBRO_de_RESUMENE S.pdf> Acesso em: 24 jun. 2018. 
FACHIN, Luiz Edson. A Cidade nuclear e o direito periférico (reflexões sobre a propriedade urbana). Revista dos tribunais, vol. 723: p.107:110, 1996.

FAORO, RAYMUNDO. Os donos do poder: formação do patronato político brasileiro. Cap. Final: A viagem redonda: do patrimonialismo ao estamento. O homem cordial. $5^{\mathrm{a}}$ ed. São Paulo: Globo, 2012. 750p.

GRIMM, Dieter. Constitucionalismo y derechos fundamentales. Traducción de Raúl Sanz Burgos y José Luis Muñoz de Baena Simón. Madrid: Editorial Trotta, 2006.

HABERMAS, Jürgen. Direito e Democracia: entre facticidade e validade. Volumes I e II. Tradução: Flávio Beno Siebeneichler. Rio de Janeiro: Tempo Brasileiro, 1997.

HARVEY, David. Cidades rebeldes: do direito a cidades à revolução urbana. São Paulo: Martins Fontes, 2014.

. O direito à cidade. Lutas Sociais no 29. São Paulo, jul./dez. 2012. p. 73-89.

HOLANDA, Sérgio Buarque. Raízes do Brasil. Cap. 5. O homem cordial. 26a ed. São Paulo: Companhia das Letras,1995. 220p.

LEFEBVRE, Henri. A cidade do capital. Tradução Maria Helena Rauta Ramos e Marilena Jamur. $2^{\mathrm{a}}$ ed. Rio de Janeiro: DO\&A, 2001.

A produção do espaço. Tradução Doralice Barros Pereira e Sergio Martins. $4^{\mathrm{a}}$ ed. Paris: Éditions Anthropos, 2006.

A revolução urbana. Tradução Sérgio Martins. Belo Horizonte: UFMG, 2008.

O Direito à cidade. Tradução Rubens Eduardo Frias. São Paulo: Centauro, 2001.

LOIS, Cecília Caballero. A filosofia constitucional de John Rawls e Jürgen Habermas: um debate sobre as relações entre sistemas de justiça e sistemas de direitos. Revista Sequência, n. ${ }^{\circ}$ 50, p.121-141, jul. 2005.

MARQUES, Clarissa. O conceito de direitos fundamentais. Direitos humanos e fundamentais em perspectiva. Cláudio Brandão, coordenador. São Paulo: Atlas, 2014, p. 151-168.

MATTIETTO, Leonardo. A renovação do direito de propriedade. Revista de Informação Legislativa. Brasília a. 42 nº 168, out./dez. 2005.

MOORE, Jason W. El in de la naturaleza barata: o cómo aprendi a dejar de preocuparme com "El" medioambiente y amar la crisis del capitalismo. Relaciones Internacionales, n. ${ }^{\circ}$ 33, p. 143-174-2017.

MOREIRA, Camilla Fernandes. Direitos humanos e políticas públicas: uma estratégia metodológica de implementação - o caso da habitação no Brasil. In: XXXI CONGRESSO

Rev. de Direito Urbanístico, Cidade e Alteridade | e-ISSN: 2525-989X | Porto Alegre | v. 4 | n. 2 | p. 53 - 67 | Jul/Dez. 2018 
ALAS URUGUAY 2017. México, 2017. Resumos... ref. 2736 Disponível em: < http://alas2017.easyplanners.info/opc/pdfs/ALAS_2017_Uruguay_LIBRO_de_RESUMENES .pdf> Acesso em: 24 jun. 2018.

NUNES, António José Avelãs. Neoliberalismo e direitos humanos. Rio de Janeiro: Renovar, 2003.

OLIVEIRA, Celso Maran de; LOPES, Dulce; SOUSA, Isabel Cristina Nunes de. Direito à participação nas políticas urbanísticas: avanços após 15 anos de estatuto da cidade. Urbe, Rev. Bras. Gest. Urbana, Curitiba, v. 10, n. 2, p. 322-334, ago. 2018 Epub 19-Fev2018. http://dx.doi.org/10.1590/2175-3369.010.002.ao04.. Disponível em: <http://www.scielo.br/scielo.php?script=sci_arttext\&pid=S217533692018000200322\&lng=pt\&nrm=iso.> Acesso em: 14 jun. 2018.

PAGANI, Eliane Barbosa Santos. Habitação de interesse social no Brasil: o programa Minha Casa Minha em Londrina/PR. In: XXXI CONGRESSO ALAS URUGUAY 2017. México, 2017. Resumos... $\quad$ ref. 4702 Disponível em: http://alas2017.easyplanners.info/opc/pdfs/ALAS_2017_Uruguay_LIBRO_de_RESUMENES .pdf> Acesso em: 24 jun. 2018.

RAMPAZZO, Lino. Princípios jurídicos e éticos em Tomás de Aquino. São Paulo: Paulus, 2015.

ROLNIK, Raquel. Guerra dos lugares: a colonização da terra e da moradia na era das finanças. São Paulo: Boitempo, 2015.

Sabe com quem está falando?: contos sobre corrupção e poder. (Machado de Assis ... et al.); organização, Luiz Ruffato. Rio de Janeiro: Língua Geral, 2012. 376p.

SANDEL, Michael J. Justiça - o que é fazer a coisa certa. Tradução de Heloísa Matias e Maria Alice Máximo. 14ª ed. Rio de Janeiro: Civilizaçã Brasileira, 2014.

SANTOS, Boaventura de Sousa. Para além do pensamento abissal: das linhas globais a uma ecologia de saberes. Novos estud. - CEBRAP [online]. 2007, n.79, pp.71-94. ISSN 01013300. http://dx.doi.org/10.1590/S0101-33002007000300004. Acesso em: 06 ago. 2018.

SANTOS, Milton. A Natureza do espaço: Técnica e Tempo, Razão e Emoção. $4^{\mathrm{a}}$ ed. São Paulo: Universidade de São Paulo, 2006.

SCHONARDIE, Elenise Felzke. A concretização dos direitos humanos e a questão dos aglomerados subnormais nas cidades brasileiras. Revista de Direito da Cidade, vol. 09, n. ${ }^{\circ} 03$, p.1363-1382. Disponível em: < http://www.epublicacoes.uerj.br/index.php/rdc/article/view/27166 > Acesso em: 24 jun. 2018.

SILVA, Gabriel Rodrigues da; CHAVES, Carina Aparecida Barbosa Mendes; CHAVES, Danilo Ferreira; TEIXEIRA, Rylanneive Leonardo Pontes. In: XXXI CONGRESSO ALAS URUGUAY 2017. México, 2017. Resumos... ref. 8369 Disponível em: < http://alas2017.easyplanners.info/opc/pdfs/ALAS_2017_Uruguay_LIBRO_de_RESUMENES .pdf> Acesso em: 24 jun. 2018. 
SILVA, Gilnei José Oliveira. Direito à moradia adequada: a (in)efetividade nas ocupações em área de risco - o beira trilha de Passo Fundo. 2006. Originalmente apresentada como dissertação de mestrado, Universidade do Vale do Rio dos Sinos, São Leopoldo: 2006. Programa de Pós-Graduação em Direito. Orientação Prof. ${ }^{\circ}$ Dr. Rodrigo Stumpf González, Ciências Jurídicas.

SOUZA, Jessé. A elite do atraso: da escravidão à Lava Jato. Rio de Janeiro: Leya, 2017.

A invisibilidade da desigualdade brasileira. Belo Horizonte: Editora UFMG, 2006.

A tolice da inteligência brasileira: ou como o país de deixa manipular pela elite. Rio de Janeiro: Leya, 2015.

Ralé brasileira: quem é e como vive. Belo Horizonte: Editora UFMG, 2009.

. Subcidadania brasileira: para entender o país além do jeitinho brasileiro. Rio de Janeiro: Leya, 2018.

SOUZA NETO, Cláudio Pereira de.; SARMENTO, Daniel. Direito Constitucional: Teoria, História e Métodos de Trabalho. Belo Horizonte: Fórum, 2014.

TEPEDINO, Gustavo (Coord.): Problemas de direito civil-constitucional. Rio de Janeiro: Renovar, 2000.

TORRES, Marcos Alcino de Azevedo. Questões urbanas. Uma reflexão sobre a ocupação do espaço urbano. O capital e a função social da cidade. In Cadernos de direito da cidade: estudos em homenagem à Professora Maria Garcia. Série 2. Rio de Janeiro: Lumen Juris, 2014.

UCHÔA, Fábio Raddi. A sociedade urbana de Henri Lefebvre. Disponível em: <http://conti.derhuman.jus.gov.ar/2011/10/mesa_4/uchoa_mesa_4.pdf>

Acesso em: 21 mar. 2018.

WOLKMER, Antonio Carlos. História do direito no Brasil. $7^{\text {a }}$ ed. Rio de Janeiro: Forense, 2014.

ZÚÑIGA, Rebeca Moreno; MONTELONGO, Mario Alberto Jurado. El proceso de renovación urbana del Centro Metropolitano de Moterrey. Artistas y activistas: habitar el centro como una forma de resistencia social. In: XXXI CONGRESSO ALAS URUGUAY 2017. México, 2017. Resumos... ref. 7718 Disponível em: <http://alas2017.easyplanners.info/opc/tl/7718_rebeca_moreno_zuniga.pdf> Acesso em: 24 jun. 2018.

Rev. de Direito Urbanístico, Cidade e Alteridade | e-ISSN: 2525-989X | Porto Alegre | v. 4 | n. 2 | p. 53 - 67 | Jul/Dez. 2018 